\title{
The effects of lean beef supplementation on the iron status of college athletes
}

\author{
This article was published in the following Dove Press journal: \\ Nutrition and Dietary Supplements \\ II July 2012 \\ Number of times this article has been viewed
}

\section{Jocelyn Johnson \\ Danielle Burke \\ Matthew Vukovich \\ Kendra Kattelmann}

Health and Nutritional Sciences Department, South Dakota State University, Brookings, SD, USA
Correspondence: Kendra Kattelmann Health and Nutritional Sciences Department, PO Box 2203,

South Dakota State University, Brookings, SD 57007, USA

Tel +l 6056884045

Fax +l 6056885603

Email kendra.kattelmann@sdstate.edu
Abstract: The purpose of this study was to determine whether weekly supplementation with nine ounces of prepackaged lean beef sticks could maintain the iron status of college endurance athletes. Thirty-four college endurance athletes (20 female, 14 male) were stratified by sex, baseline serum ferritin concentration, and use of iron supplements, and randomized into an intervention $(\mathrm{n}=18)$ or control $(\mathrm{n}=16)$ group. The participants in the intervention group supplemented their usual diet with nine ounces of prepackaged lean beef sticks per week and a daily multivitamin/mineral supplement containing $18 \mathrm{mg}$ iron. The participants in the control group consumed their normal diet and the daily multivitamin/mineral supplement only. Body composition, dietary intake, and blood markers of iron status (hemoglobin, hematocrit, serum iron, serum ferritin, and total iron binding capacity) were measured at baseline and postintervention. A two-way analysis of variance with group and time as treatment factors was used to determine the main effect of beef supplementation on variables measured. None of the participants in this study was categorized as iron deficient at baseline or postintervention. Heme iron intake was significantly greater $(P<0.003)$ in the intervention group $(3.1 \pm 0.3 \mathrm{mg}$ per day $)$ than in the control group $(1.5 \pm 0.3 \mathrm{mg}$ per day) as a result of the intervention. The intervention participants had significant improvements in hematocrit concentrations; there were, however, no differences in blood iron parameters of serum iron, hemoglobin, serum ferritin, or total iron binding capacity as a result of the intervention. The results of this study suggest that daily intake of bioavailable iron may attenuate the effects of exercise on the iron status of endurance athletes.

Keywords: bioavailable iron, iron status, iron deficiency, heme iron, endurance athletes, lean beef

\section{Introduction}

Iron deficiency (ID), with or without anemia, continues to be one of the most widespread and severe nutritional deficiencies in the world today, affecting more than $30 \%$ of the world's population. ${ }^{1}$ Iron deficiency is characterized by a depletion of the body's iron stores, which results in a restricted supply of iron to the tissues. ${ }^{2}$ Iron deficiency anemia (IDA) occurs when iron stores become sufficiently depleted, causing the hemoglobin (Hb) concentration of the blood to decrease, with resultant adverse health effects. ${ }^{3}$ The incidence of IDA in the United States is higher among women of childbearing age $(3 \%-5 \%)$ than among adult men $(<1 \%)$, and ID without anemia is more frequent than IDA, occurring in $12 \%-16 \%$ of women and $2 \%$ of men. ${ }^{4,5}$

Athletes, especially endurance athletes, tend to have a significantly increased prevalence of iron deficiency when compared to the general population. ${ }^{5}$ Several 
studies have reported low serum ferritin levels $(<25 \mu \mathrm{g} / \mathrm{L}$ or $<35 \mu \mathrm{g} / \mathrm{L})$ in a large percentage of long-distance runners. ${ }^{6,7}$ Athletes are at increased risk for poor iron status, because of the combined effects of a higher demand for iron with increased blood volume and muscle mass, as well as increased iron losses due to foot-strike hemolysis, gastrointestinal blood loss, and losses through sweating. ${ }^{5,8-10}$ Female athletes are more susceptible to iron deficiency than male athletes, due to additional losses through menses and intrauterine contraceptive use. ${ }^{5}$ Low iron levels result in impaired oxygen transport, which decreases endurance capacity and energetic efficiency and, therefore, is detrimental to athletic performance. $^{11}$

One of the most significant factors contributing to iron status is the balance between an individual's iron requirements and iron intake. ${ }^{12}$ The recommended dietary allowance (RDA) for all men and postmenopausal women is $8 \mathrm{mg} /$ day of iron, and the RDA for premenopausal women is $18 \mathrm{mg} /$ day. The median daily intake of iron is $16-18 \mathrm{mg}$ /day for men and $12 \mathrm{mg} /$ day for women, ${ }^{13}$ which indicates that, while men usually consume an adequate amount of iron, most women do not achieve the daily recommended amount. Dietary iron exists as heme iron (from animal-based sources) or non-heme iron (from plant and dairy foods or supplements). Heme iron is highly bioavailable compared to non-heme iron, and its absorption is affected very little by dietary factors. ${ }^{13}$ Meat products not only have a high content of heme iron, but they also increase the absorption of both heme and non-heme iron. ${ }^{14}$

Endurance athletes, especially distance runners, tend to consume diets that are low in dietary fat and high in carbohydrates. ${ }^{10}$ Iron intake is generally lower in a low-fat diet, ${ }^{15}$ and routine consumption of a plant-based diet comprised of protein foods containing mostly non-heme iron can negatively affect iron status over time. ${ }^{16}$ Red meat (beef) contains higher amounts of heme iron than poultry, ${ }^{14}$ but it can be expensive and time-consuming to prepare. Preliminary data from a recent study suggest that even with knowledge of proper preparation methods and cooking skills, time constraints limit the amount of beef consumed by college-aged individuals (Olson et al, unpublished data, April 15, 2012). This is especially true for athletes, who are likely to eat between five and ten small meals per day to meet the additional energy requirements of daily training, while avoiding the gastric discomfort associated with consuming large meals. ${ }^{17}$

Dietary interventions that increase the intake of bioavailable iron have been effective in improving the iron status of individuals with low iron stores. ${ }^{18}$ The addition of small amounts of prepackaged lean beef to an athlete's diet might provide a highly absorbable form of iron that is easily accessible and portable. Therefore, the purpose of this study was to determine whether supplementation with a prepackaged lean beef stick, in addition to a multivitamin/mineral supplement containing iron, would maintain the iron status of college athletes over the competitive season. The working hypothesis was that supplementation with a prepackaged lean beef stick and multivitamin/mineral supplement containing iron would be more effective in maintaining iron stores than supplementation with a multivitamin/mineral alone.

\section{Methods}

\section{Subjects}

Male and female college athletes, 18-24 years of age, were recruited from the track, cross-country, and volleyball teams at South Dakota State University, with approval from the head coach. Female participants were not pregnant or lactating. Individuals who consented to participate were willing to consume lean beef and discontinue personal use of multivitamin/mineral supplements. Use of iron supplements was documented and allowed to continue, in order to avoid interference with recommendations from the head coach. Participants were required to complete a general health history questionnaire. This study was approved by the South Dakota State University Institutional Review Board, and all participants were required to provide informed consent upon enrollment in the study.

\section{Study design}

Participants were stratified based on sex, current use of iron supplements, and baseline serum ferritin levels, and they were randomized into an intervention or control group. The intervention for this study was eight weeks in length. Participants randomized into the intervention group were required to consume nine one-ounce prepackaged lean beef sticks (Silver Creek Specialty Meats, Inc, Oshkosh, WI) per week, in addition to a daily multivitamin/mineral supplement (Equate Complete Multivitamin/Mineral; Wal-Mart Stores, Inc, Bentonville, AR) containing $18 \mathrm{mg}$ iron as ferrous sulfate. The control group consumed the daily multivitamin/ mineral supplement only. The participants in both groups were instructed to maintain their normal diets in addition to the supplements. The beef supplement and multivitamin/ mineral supplement provided $6 \%$ and $100 \%$, respectively, of the RDA for iron. The multivitamin/mineral supplements were distributed to both groups at baseline, and the intervention group received a two-week supply $(n=18)$ of beef sticks on a biweekly basis. Participants in both groups were 
required to fill out a weekly record annotating consumption of the beef sticks and/or multivitamin/mineral supplements. Records were collected and monitored by study personnel on a biweekly basis. Participants in both groups were advised to maintain typical dietary patterns and continue exercising according to their usual training regimen.

\section{Blood sampling protocol}

A blood sample was required from all participants at baseline and at the end of the eight-week intervention period. Participants were advised to fast for at least 12 hours prior to their scheduled blood draw. Sampling was performed by qualified personnel using sterile techniques. Duplicate samples of approximately $15 \mathrm{~mL}$ of blood were obtained from the antecubital vein via venipuncture and collected in EDTA tubes. Whole blood samples were analyzed immediately after collection for hemoglobin concentration and hematocrit percentage. Hemoglobin was measured using the cyanmethemoglobin method (H7504; Pointe Scientific, Inc, Canton, MI), and the standard microcentrifuge technique was used to measure hematocrit. Serum was recovered through centrifugation, stored at $-40^{\circ} \mathrm{C}$, and later assayed for the following biochemical indicators of iron status: serum ferritin, serum iron, and total iron binding capacity. Serum iron was measured using colorimetric assays (H7504). Total iron binding capacity was calculated from the serum iron concentration. Radioimmunoassay (DSL-3000; Diagnostic Systems Laboratories, Webster, TX) was used to assess serum ferritin levels. C-reactive protein (CRP) levels were assessed to test for the presence of inflammation, using a C-Reactive Protein Ultra Sensitive ELISA Kit (Calbiotech, Inc, Spring Valley, CA). For the purpose of this study, serum ferritin levels $<15 \mu \mathrm{g} / \mathrm{L}$ indicated iron deficiency. Iron deficiency anemia was classified by hemoglobin $<12 \mathrm{~g} / \mathrm{dL}$ for women and $<13 \mathrm{~g} / \mathrm{dL}$ for men. ${ }^{1}$

\section{Body composition protocol}

Body composition testing was required of all participants at baseline and at the end of the intervention period. Body composition was determined using air displacement plethysmography, (BOD POD ${ }^{\circledR}$; Life Measurement Inc, Concord, CA). Subjects were required to refrain from food, water, and exercise for at least two hours prior to testing. All jewelry, eyeglasses, and other types of accessories were removed before entering the BOD POD. Subjects were advised to wear a swimsuit or spandex and swim cap for testing. Weight was measured using the BOD POD scale; the BOD POD was calibrated prior to each test. Subjects were instructed to enter the BOD POD chamber, sit very still, and breathe normally. The system performed a minimum of two trials, and the mean of these values was used in analysis. Body-fat percentage and lean mass were calculated and recorded for each participant.

\section{Dietary protocol}

Subjects were required to complete a three-day diet record at baseline and at eight weeks. The three-day diet record was used to assess usual nutrient intake. Participants were advised on how to estimate portion sizes and accurately record intake of food and beverages. The diet records were entered into nutritional analysis software, Food Processor for Windows 2006 (database version 10.2; ESHA Research, Salem, OR). Average intake of calories, carbohydrate, protein, fat, vitamin $\mathrm{C}$, calcium, zinc, copper, total iron, heme iron, and non-heme iron were evaluated. Heme content was calculated as $40 \%$ of the total iron content from meat products. ${ }^{19}$ In addition, participants taking an iron supplement were asked to document the type and dose.

\section{Statistical analysis}

Statistical analysis was performed using commercially available statistical software $\left(\mathrm{JMP}^{\circledR} 7\right.$; SAS Institute, Cary, NC). Descriptive statistics were represented by mean \pm standard error. A two-way analysis of variance with time and group (intervention versus control) was used to determine the main effect of beef supplementation on the variables measured. Tukey's post-hoc test was used to identify significant differences when a significant F-ratio was obtained for the group $\times$ time interaction. Statistical significance was set at $P<0.05$.

\section{Results Subject characteristics}

A total of 34 participants completed the study: 18 in the intervention group and 16 in the control group. Twenty-eight participants were recruited from the track and cross-country teams, and six were recruited from the volleyball team. The intervention group was significantly heavier and had less fat-free mass and more body fat than the control group (Table 1). Both groups had significantly increased body fat and decreased fat-free mass as an effect of time. However, the intervention group gained less body fat and lost less fat-free mass compared to the control group (Table 1).

\section{Nutrient intake}

Due to the beef supplementation, the intervention group had significantly greater intake of total iron, heme iron, and 
Table I Anthropometrics of participants at baseline and postintervention

\begin{tabular}{|c|c|c|c|c|c|}
\hline & $\begin{array}{l}\text { Intervention }{ }^{\mathrm{a}} \\
(\mathrm{n}=18)\end{array}$ & $\begin{array}{l}\text { Control }^{a} \\
(n=16)\end{array}$ & $\begin{array}{l}\text { Group } \\
\text { P-value }\end{array}$ & $\begin{array}{l}\text { Time }^{\mathrm{b}} \\
P \text {-value }\end{array}$ & $\begin{array}{l}\text { Group } \times \text { time }^{\mathrm{b}} \\
\text { P-value }\end{array}$ \\
\hline \multicolumn{6}{|c|}{ Height (in) } \\
\hline Baseline & $69.1 \pm 0.0$ & $68.0 \pm 0.0$ & 0.0001 & 0.207 & 0.207 \\
\hline Post & $69.2 \pm 0.0$ & $68.0 \pm 0.0$ & & & \\
\hline \multicolumn{6}{|c|}{ Weight (lb) } \\
\hline Baseline & $143.2 \pm 0.6$ & $139.8 \pm 0.6$ & 0.0001 & 0.195 & 0.119 \\
\hline Post & $145.2 \pm 0.7$ & $139.6 \pm 0.8$ & & & \\
\hline \multicolumn{6}{|c|}{ Body fat (\%) } \\
\hline Baseline & $15.0 \pm 0.4$ & $13.2 \pm 0.5$ & 0.025 & 0.014 & 0.350 \\
\hline Post & $15.9 \pm 0.5$ & $15.1 \pm 0.6$ & & & \\
\hline \multicolumn{6}{|c|}{ Fat-free mass (\%) } \\
\hline Baseline & $85.0 \pm 0.4$ & $86.8 \pm 0.5$ & 0.025 & 0.014 & 0.350 \\
\hline Post & $84.1 \pm 0.5$ & $84.9 \pm 0.6$ & & & \\
\hline
\end{tabular}

Notes: ${ }^{a}$ Values reported as mean \pm SEM. Control participants maintained typical diet and consumed one multivitamin supplement/day. Intervention participants added nine ounces of lean beef supplement/week to typical diet and consumed one multivitamin supplement/day;. ${ }^{\circ}$-value determined using two-way analysis of variance (ANOVA) with group and time. Significance set at $P<0.05$. Group $=$ between group differences, time $=$ within group differences, group $\times$ time $=$ interaction between group and time.

Abbreviations: in, inches; lb, pounds; SEM, standard error of the mean.

milligrams of iron per $1000 \mathrm{kcal}$ when compared to the control group (Table 2). Heme iron intake increased significantly ( $2.1 \pm 0.3$ to $3.1 \pm 0.3 \mathrm{mg}$ ) in the intervention group from baseline to postintervention, while there was no change in the control group. There were no differences between the groups in intake of calories, carbohydrates, protein, fat, non-heme iron, copper, zinc, or vitamin C. The intervention group decreased their calcium intake significantly from baseline to postintervention, and both groups consumed significantly less zinc at postintervention compared to baseline.

\section{Blood iron parameters}

Intervention participants had significant improvements in hematocrit concentrations. However, there were no differences in blood iron parameters of serum iron, hemoglobin, serum ferritin, or total iron binding capacity as a result of the intervention (Table 3). Both groups experienced decreases in serum iron, hemoglobin, and serum ferritin concentrations from baseline to postintervention. There were no sex-based differences in the iron parameters measured at baseline or postintervention. There were no significant changes in CRP concentrations for either group throughout the duration of the study.

\section{Discussion}

The purpose of this study was to determine whether supplementation with nine ounces of lean beef per week would maintain the iron status of college endurance athletes during the competitive season. The results of this study suggest that daily supplementation with bioavailable iron may attenuate the effects of exercise on the iron status of endurance athletes.
At baseline, none of the 34 participants were iron deficient (serum ferritin $<15 \mu \mathrm{g} / \mathrm{dL}$ ) or anemic (hemoglobin $<12 \mathrm{~g} / \mathrm{dL}$ ). These results are supported by the findings of Weight et al, who observed anemia in only three of 120 endurance runners. ${ }^{20}$ In the present study, the intervention group continuously met the RDA (18 $\mathrm{mg}$ ) for daily iron intake, while the control group decreased to below the RDA postintervention. Compliance with supplementation was maintained by attendance at biweekly meetings and annotation of daily supplement consumption, using weekly calendars. By consuming the additional nine ounces of beef per week, the intervention group was able to increase their average daily heme iron intake by approximately $48 \%$ from baseline.

Both groups had significant decreases in serum iron and hemoglobin over time, which was most likely due to intense training over the course of the competitive season. This outcome is in agreement with the findings of Newhouse and Clement, who conducted a review of 21 studies on athletes and iron status, 20 of which demonstrated a high incidence of low hemoglobin values. ${ }^{21}$ Hemoglobin concentration decreased to below the normal value in both groups; in the intervention group, however, this decreased by only $11 \%$, compared to a $14 \%$ decrease in the control group $(P=0.009)$. Serum iron and hematocrit remained in the normal range for both groups throughout the study, although the hematocrit values were rather low (39.7\%-42.4\%). Dressendorfer et al and Weight et al have explained this incidence of "pseudoanemia" (low hemoglobin levels and coexistent normal body iron stores) on training-induced hemodilution, in which plasma volume increases more quickly and to a greater degree than the 
Table 2 Nutrient analysis of participants' dietary intake from food at baseline and postintervention

\begin{tabular}{|c|c|c|c|c|c|}
\hline & $\begin{array}{l}\text { Intervention }{ }^{a} \\
(n=18)\end{array}$ & $\begin{array}{l}\text { Control }{ }^{a} \\
(n=16)\end{array}$ & $\begin{array}{l}\text { Group }^{b} \\
\text { P-value }\end{array}$ & $\begin{array}{l}\text { Time }^{\mathrm{b}} \\
\text { P-value }\end{array}$ & $\begin{array}{l}\text { Group } \times \text { time }^{\mathrm{b}} \\
P \text {-value }\end{array}$ \\
\hline \multicolumn{6}{|c|}{ Calories (kcal/day) } \\
\hline Baseline & $2843.0 \pm 211.4$ & $2659.4 \pm 226.0$ & 0.511 & $0.78 \mathrm{I}$ & 0.161 \\
\hline Post & $2572.8 \pm 223.7$ & $3060.4 \pm 257.0$ & & & \\
\hline \multicolumn{6}{|c|}{ Carbohydrates (g/day) } \\
\hline Baseline & $367.0 \pm 26.4$ & $344.9 \pm 28.3$ & 0.260 & 0.962 & 0.070 \\
\hline Post & $3 \mid 3.4 \pm 28.0$ & $401.2 \pm 32.1$ & & & \\
\hline \multicolumn{6}{|c|}{ Protein (g/day) } \\
\hline Baseline & $104.9 \pm 5.2$ & $103.9 \pm 5.5$ & 0.891 & 0.978 & 0.971 \\
\hline Post & $104.5 \pm 5.5$ & $103.9 \pm 6.3$ & & & \\
\hline \multicolumn{6}{|c|}{ Fat (g/day) } \\
\hline Baseline & $100.0 \pm 11.6$ & $96.6 \pm 12.4$ & 0.356 & 0.750 & 0.245 \\
\hline Post & $89.0 \pm 12.2$ & $|15.9 \pm 14|$. & & & \\
\hline \multicolumn{6}{|c|}{ Total iron (mg) } \\
\hline Baseline & $22.5 \pm 2.0$ & $18.2 \pm 2.1$ & 0.035 & 0.692 & 0.856 \\
\hline Post & $22.1 \pm 2.1$ & $16.9 \pm 2.4$ & & & \\
\hline \multicolumn{6}{|c|}{ Heme iron (mg) } \\
\hline Baseline & $2.1 \pm 0.3^{x}$ & $1.8 \pm 0.3^{x}$ & 0.003 & 0.174 & 0.042 \\
\hline Post & $3.1 \pm 0.3^{y}$ & $1.5 \pm 0.3^{x}$ & & & \\
\hline \multicolumn{6}{|c|}{ Non-heme iron (mg) } \\
\hline Baseline & $20.5 \pm 1.9$ & $16.4 \pm 2.1$ & 0.080 & 0.559 & 0.922 \\
\hline Post & $19.0 \pm 2.1$ & $15.4 \pm 2.4$ & & & \\
\hline \multicolumn{6}{|c|}{ Iron (mg// $000 \mathrm{kcal})$} \\
\hline Baseline & $8.3 \pm 0.9$ & $6.9 \pm 0.9$ & 0.032 & 0.974 & 0.423 \\
\hline Post & $9.0 \pm 0.9$ & $6.1 \pm 1.1$ & & & \\
\hline \multicolumn{6}{|c|}{ Copper (mg) } \\
\hline Baseline & $0.7 \pm 0.1$ & $0.8 \pm 0.1$ & 0.862 & 0.310 & 0.180 \\
\hline Post & $0.8 \pm 0.1$ & $0.6 \pm 0.1$ & & & \\
\hline \multicolumn{6}{|c|}{ Calcium (mg) } \\
\hline Baseline & $1519.6 \pm 71.7^{x}$ & $1149.1 \pm 76.6^{y}$ & 0.408 & 0.002 & 0.0007 \\
\hline Post & $932.7 \pm 75.8^{y}$ & $1173.2 \pm 87 .\left.\right|^{x y}$ & & & \\
\hline \multicolumn{6}{|c|}{ Zinc (mg) } \\
\hline Baseline & $12.6 \pm 1.2$ & $10.5 \pm 1.3$ & 0.181 & 0.008 & 0.835 \\
\hline Post & $8.5 \pm 1.3$ & $6.9 \pm 1.5$ & & & \\
\hline \multicolumn{6}{|c|}{ Vitamin C (mg) } \\
\hline Baseline & $67.0 \pm 6.3$ & $69.1 \pm 6.7$ & 0.132 & 0.219 & 0.232 \\
\hline Post & $49.8 \pm 6.7$ & $68.9 \pm 7.7$ & & & \\
\hline
\end{tabular}

Notes: aValues reported as mean \pm SEM. Control participants maintained typical diet and consumed one multivitamin supplement/day. Intervention participants added nine ounces of lean beef supplement/week to typical diet and consumed one multivitamin supplement/day; ${ }^{b}$-value determined using two-way analysis of variance (ANOVA) with group and time. Means with differing letters $(x y)$ are significantly different (Tukey's post-hoc). Significance set at $P<0.05$. Group $=$ between group differences, time $=$ within group differences, group $\times$ time $=$ interaction between group and within group change.

Abbreviation: SEM, standard error of the mean.

increase in red cell volume. ${ }^{22,23}$ This hemodilution can persist indefinitely in athletes engaged in high-energy training, especially those involved in endurance sports. ${ }^{24}$ Rushall and Busch performed a study on elite swimmers, in which they found that periods of intense training were coupled with decreased hemoglobin and hematocrit values. ${ }^{25}$

Serum ferritin is a more accurate indicator of iron status, because it is not affected by the hemodilution that can occur in athletes involved in training, and it is not variable from day to day. Both groups had normal ferritin levels throughout the duration of the study. In addition, ferritin concentration increased significantly from baseline, by $28 \%$ and $21 \%$ in the intervention and control groups, respectively. These results are in opposition to several studies that have reported a high incidence of low serum ferritin levels in endurance athletes. In a study by Nachtigall et al, over $50 \%$ of the endurance runners had serum ferritin levels lower than $35 \mu \mathrm{g} / \mathrm{L} .{ }^{6}$ Extremely low ferritin levels $(<25 \mu \mathrm{g} / \mathrm{L})$ were found in $29 \%$ of male and $82 \%$ of female elite long-distance runners in a study by Clement et al. ${ }^{7}$ A potential explanation for the serum ferritin levels in the current study is that they were increased due to inflammation caused by habitual training. Ferritin is an 
Table 3 Blood-iron parameters of participants in the intervention and control groups at baseline and postintervention

\begin{tabular}{|c|c|c|c|c|c|}
\hline & $\begin{array}{l}\text { Intervention }^{a} \\
(\mathrm{n}=18)\end{array}$ & $\begin{array}{l}\text { Control }^{a} \\
(n=16)\end{array}$ & $\begin{array}{l}\text { Group }^{b} \\
\text { P-value }\end{array}$ & $\begin{array}{l}\text { Time }^{\mathrm{b}} \\
\text { P-value }\end{array}$ & $\begin{array}{l}\text { Group } \times \text { time }^{\mathrm{b}} \\
\text { P-value }\end{array}$ \\
\hline \multicolumn{6}{|c|}{ Serum iron $(\mu \mathrm{g} / \mathrm{dL})$} \\
\hline Baseline & $117.7 \pm 9.9$ & $131.7 \pm 11.7$ & 0.132 & 0.002 & 0.801 \\
\hline Post & $78.7 \pm 9.9$ & $98.2 \pm 11.7$ & & & \\
\hline \multicolumn{6}{|c|}{ Hemoglobin (g/dL) } \\
\hline Baseline & $12.8 \pm 0.5$ & $13.5 \pm 0.6$ & 0.457 & 0.009 & 0.628 \\
\hline Post & $1 \mathrm{I} .4 \pm 0.6$ & $11.6 \pm 0.7$ & & & \\
\hline \multicolumn{6}{|c|}{ Hematocrit (\%) } \\
\hline Baseline & $39.7 \pm 0.8^{z}$ & $42.4 \pm 0.9^{x y}$ & 0.792 & 0.950 & 0.012 \\
\hline Post & $42.2 \pm 0.9^{x y}$ & $40.0 \pm 1.0^{x y z}$ & & & \\
\hline \multicolumn{6}{|c|}{ Serum ferritin $(\mu \mathrm{g} / \mathrm{L})$} \\
\hline Baseline & $56.7 \pm 4.6$ & $56.1 \pm 5.2$ & 0.624 & 0.015 & 0.702 \\
\hline Post & $72.8 \pm 4.9$ & $68.0 \pm 6.5$ & & & \\
\hline \multicolumn{6}{|c|}{ TIBC $(\mu \mathrm{mol} / \mathrm{L})$} \\
\hline Baseline & $73.0 \pm 2.9$ & $77.6 \pm 3.2$ & 0.027 & 0.427 & 0.404 \\
\hline Post & $67.9 \pm 2.9$ & $77.7 \pm 3.4$ & & & \\
\hline
\end{tabular}

Notes: ${ }^{a}$ Values reported as mean \pm SEM. Control participants maintained typical diet and consumed one multivitamin supplement/day. Intervention participants added nine

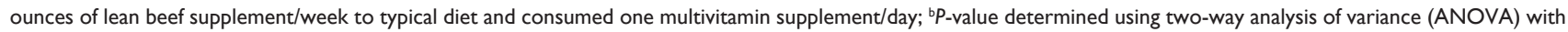
group and time. Means with differing letters (xyz) are significantly different (Tukey's post-hoc). Significance set at $P<0.05$. Group $=$ between group differences, time $=$ within group differences, group $\times$ time $=$ interaction between group and within group change.

Abbreviations: TIBC, total iron binding capacity; SEM, standard error of the mean.

acute-phase protein, and several studies have shown that exercise results in an inflammatory state, which can increase serum ferritin levels considerably. ${ }^{6,27,28}$ This increase in serum ferritin occurs rapidly and can last for several days, and even weeks. ${ }^{6}$ In the current study, CRP levels were measured and found to be insignificant. However, CRP may be a poor indicator of inflammation in relation to ferritin, as the half-life of CRP is $5-7$ hours, compared to 30 hours for ferritin. ${ }^{29,30}$ Therefore, decreases in CRP are not necessarily paralleled by decreases in serum ferritin.

The reported significant difference in calcium intake seen in the control group was due to a decrease in the group's dairy consumption at the postintervention data collection. Calcium inhibits the absorption of both heme and non-heme iron, and it may have the capability to alter serum ferritin concentrations. ${ }^{31}$ However, this inhibitory effect of calcium on iron absorption might only occur at high calcium intake levels. Little effect has been observed on serum ferritin concentrations when calcium intakes range from 1,000 to $1,500 \mathrm{mg} /$ day. ${ }^{32,33}$ Although there were differences in calcium intake between the groups, it was not believed that this result would impact the iron outcome, as the participants' consumption of calcium was within the recommended ranges.

A practical method for preventing a decrease in body iron stores is to consume a diet rich in bioavailable iron. Lyle et al found that consumption of one meat-containing meal per day was effective in maintaining serum ferritin levels during prolonged, modest exercise. ${ }^{32}$ In a study by Tetens et al, women of childbearing age who consumed a meat-based diet were able to maintain serum ferritin, while it declined in those who consumed a vegetable-based diet..$^{33}$ The results of these studies are consistent with the results of the present study. By consuming an additional nine ounces of bioavailable iron per week, the intervention group was able to maintain their iron status, despite intense daily training.

Athletes, especially those undergoing strenuous endurance training, are at risk for ID and IDA, due to several factors. ${ }^{34}$ Iron deficiency is detrimental to athletes because low hemoglobin concentrations impair the transport of oxygen to muscle tissue, which can negatively affect work performance. ${ }^{11}$ Unfortunately, the changes in hematological indicators caused by exercise can make it difficult to accurately assess iron status. In addition, research has shown that long-distance runners tend to eat small, frequent meals that are high in carbohydrates and low in fat. ${ }^{10,15,18}$ It has been suggested that very high-carbohydrate and low-fat diets might be low in protein and contain inadequate sources of micronutrients such as iron and zinc. ${ }^{15}$ Increased iron requirements, in combination with low bioavailable iron intake, can amplify the risk of developing iron deficiency, with or without anemia. Previous research has shown that increasing the intake of bioavailable iron though dietary intervention was effective in improving the iron status of individuals with low stores. ${ }^{19}$ The results of this study suggest that daily supplementation with bioavailable iron may attenuate the negative 
effects of exercise on the iron status of endurance athletes. In addition, the findings of this study imply that an easily accessible and portable form of lean beef is an efficient way to supplement time-constrained college athletes with highly absorbable heme iron.

\section{Acknowledgments}

The funding for this research was provided by the South Dakota Beef Council and the South Dakota Agricultural Experiment Station, South Dakota State University, Brookings, South Dakota, USA.

\section{Disclosure}

The authors report no conflicts of interest in this paper.

\section{References}

1. WHO/UNU/UNICEF. Iron Deficiency Anemia: Assessment, Prevention, and Control. A Guide for Program Managers. Geneva: World Health Organization; 2001 (WHO/NHD/01.3).

2. Bothwell TH, Charlton RW, Cook JB, Finch CA. Iron Metabolism in Man. Oxford, United Kingdom: Blackwell Scientific; 1979.

3. Chandyo RK, Strand TA, Ulvik RJ, et al. Prevalence of iron deficiency and anemia among healthy women of reproductive age in Bhaktapur, Nepal. Eur J Clin Nutr. 2007;61(2):262-269.

4. Looker AC, Dallman PR, Carroll MD, Gunter EW, Johnson CL. Prevalence of iron deficiency in the United States. JAMA. 1997;277(12): 973-976.

5. Sinclair LM, Hinton PS. Prevalence of iron deficiency with and without anemia in recreationally active men and women. $J$ Am Diet Assoc. 2005;105(6):975-978.

6. Nachtigall D, Nielsen P, Fischer R, Engelhardt R, Gabbe EE. Iron deficiency in distance runners. A reinvestigation using Fe-labeling and noninvasive liver iron quantification. Int J Sports Med. 1996;17(7):473-479.

7. Clement DB, Asmundson RC, Medhurst CW. Hemoglobin values: comparative survey of the 1976 Canadian Olympic team. Can Med Assoc J. 1977;117(6):614-616.

8. Weaver CM, Rajaram S. Exercise and iron status. J Nutr. 1992; 122(Suppl 3):782-787.

9. Blum S, Sherman A, Boileau R. The effects of fitness-type exercise on iron status in adult women. Am J Clin Nutr. 1986;43(3):456-463.

10. Nielsen P, Nachtigall D. Iron supplementation in athletes: Current recommendations. Sports Med. 1998;26(4):207-216.

11. Di Santolo M, Stel G, Banfi G, Gonano F, Cauci S. Anemia and iron status in young fertile non-professional female athletes. Eur J Appl Physiol. 2008;102(6):703-709.

12. Beard J, Tobin B. Iron status and exercise. Am J Clin Nutr. 2000; 72(Suppl 2):594S-597S.

13. Institute of Medicine, Food and Nutrition Board. Dietary Reference Intakes for Vitamin A, Vitamin K, Arsenic, Boron, Chromium, Copper, Iodine, Iron, Manganese, Molybdenum, Nickel, Silicon, Vanadium, and Zinc. Washington, DC: National Academy Press; 2001.

Nutrition and Dietary Supplements

\section{Publish your work in this journal}

Nutrition and Dietary Supplements is an international, peer-reviewed, open access journal focusing on research into nutritional requirements in health and disease, impact on metabolism and the identification and optimal use of dietary strategies and supplements necessary for normal growth and development. The journal welcomes papers covering
14. López MA, Martos FC. Iron availability: An updated review. Int J Food Sci Nutr. 2004;55(8):597-606.

15. Venkatraman J, Pendergast D. Effect of dietary intake on immune function in athletes. Sports Med. 2002;32(5):323-337.

16. Weight LM, Jacobs P, Noakes TD. Dietary iron deficiency and sports anaemia. Br J Nutr. 1992;68(1):253-260.

17. Hawley JA, Burke LM. Effect of meal frequency and timing on physical performance. Br J Nutr. 1997;77(Suppl 1):S91-S103.

18. Heath AL, Skeaff CM, O'Brien SM, Williams SM, Gibson RS. Can dietary treatment of non-anemic iron deficiency improve iron status? $J$ Am Coll Nutr. 2001;20(5):477-484.

19. Cook JD, Monsen ER. Food iron absorption in human subjects. III. Comparison of the effects of animal proteins on non-heme animal absorption. Am J Clin Nutr. 1976;29(8):859-867.

20. Weight LM, Alexander D, Elliot T, Jacobs P. Erythropoietic adaptations to endurance training. Eur J Appl Physiol Occup Physiol. 1992;64(5):444-448.

21. Newhouse IJ, Clement DB. Iron status in athletes: an update. Sports Med. 1988;5(6):337-352.

22. Dressendorfer RH, Keen CL, Wade CE, Claybaugh JR, Timmis GC. Development of runner's anemia during a 20-day road race: effect of iron supplements. Int J Sports Med. 1991;12(3):332-336.

23. Weight LM, Darge BL, Jacobs P. Athletes' pseudoanaemia. Eur J Appl Physiol Occup Physiol. 1991;62(5):358-362.

24. Chatard JC, Mujika I, Guy C, Lacour JR. Anaemia and iron deficiency in athletes: Practical recommendations for treatment. Sports Med. 1999;27(4):229-240.

25. Rushall BS, Busch JD. Hematological responses to training in elite swimmers. Can J Appl Sports Sci. 1980;5(3):164-169.

26. Weight LM, Alexander D, Jacobs P. Strenuous exercise: analogous to the acute-phase response? Clin Sci (Lond). 1991;81(5):677-683.

27. Balaban EP, Snell P, Stray-Gundersen J, Frenkel EP. The effect of running on serum and red cell ferritin: a longitudinal comparison. Int J Sports Med. 1995;16(5):278-282.

28. Pattini A, Schena F, Guidi GC. Serum ferritin and serum iron changes after cross-country and roller ski endurance races. Eur J Appl Physiol Occup Physiol. 1990;61(1-2):55-60.

29. Hallberg L, Brune M, Erlandsson M, Sandberg AS, Rossander-Hulthen L. Calcium: effect of different amounts of nonheme- and heme-iron absorption in humans. Am J Clin Nutr. 1991;53(1):112-119.

30. Ames SK, Gorham BM, Abrams SA. Effects of high compared with low calcium intake on calcium absorption and incorporation of iron by red blood cells in small children. Am J Clin Nutr. 1999;70(1):44-48.

31. Dalton MA, Sargent JD, O'Connor GT, Olmstead EM, Klein RZ. Calcium and phosphorus supplementation of iron-fortified infant formula: no effect on iron status of healthy full-term infants. Am J Clin Nutr. 1997;65(4):921-926.

32. Lyle RM, Weaver CM, Sedlock DA, Rajaram S, Martin B, Melby CL. Iron status in exercising women: the effect of oral iron therapy vs increased consumption of muscle foods. Am J Clin Nutr. 1992;56(6): 1049-1055.

33. Tetens I, Bendtsen K, Henriksen M, Ersboll A, Milman N. The impact of a meat- versus a vegetable-based diet on iron stats in women of childbearing age with small iron stores. Eur J Nutr. 2007;46(8):439-445.

34. Magazanik A, Weinstein Y, Dlin R, Derin M, Schwartzman S, Allalouf D. Iron deficiency caused by 7 weeks of intensive physical exercise. Eur $J$ Appl Physiol Occup Physiol. 1988;57(2):198-202.

\section{Dovepress}

original research, basic science, clinical \& epidemiological studies, reviews and evaluations, guidelines, expert opinion and commentary, case reports and extended reports. The manuscript management system is completely online and includes a very quick and fair peer-review system, which is all easy to use. 